Information Management and Business Review

Vol. 4, No. 6, pp. 340-351, June 2012 (ISSN 2220-3796)

\title{
Gender Role Portrayal in Television Advertisement: Evidence from Pakistan
}

\author{
Abid Ali ${ }^{1}$, ${ }^{*}$ Raza Ali ${ }^{1}$, Dileep Kumar ${ }^{2}$, Muhammad Haroon Hafeez ${ }^{2}$, Bushra Ghufran ${ }^{3}$ \\ ${ }^{1}$ Bahauddin Zakariya University, Multan, Pakistan \\ 2Universiti Utara Malaysia, College of Business, Sintok, Malaysia \\ ${ }^{3}$ Air University Multan, Pakistan \\ *R.Ali@mdx.ac.uk
}

\begin{abstract}
This study aims to observe the gender role portrayal in food and non-food television advertisement in Pakistan, in order to find out gender discrimination (if any) and association of gender with different content variables. Content analysis of selected TV commercials was used to fulfill the purpose of this study. Services of two independent coders (business graduates) were utilized to code content variables for a sample of 103 commercials (54 food and 49 non-food commercials). Based on the extant literature, seven content variables were selected for this study including: main product user, voiceover, primary character, end comment, soundtrack level, activity level and aggression level. The gender role portrayals in both food and non-food commercials have been compared and discussed. There exists gender discrimination in Pakistani television advertisement, where males dominate more. The reason behind this phenomenon is expected to lie in social and cultural values. This male dominance is higher in food advertisement as compared to non-food advertisement. Results also favor the association of male character with the relatively higher activity and aggression levels in television commercials. The findings of this study are supportive for key players in advertising industry like advertisers and advertising agencies, for self-regulation of their advertising campaigns with respect to gender role. However, more important implication for them is to know about the forces of traditional cultural values and preferences of target audience, for effective planning of the commercials and forecasting their impact. Such knowledge can provide them a better base to assess the need for self-regulation of their advertising campaigns, guiding them towards making more successful commercials. This study reflects the true picture of gender discrimination in Pakistani television advertisement. It has been concluded using a well defined methodology, provides original data for Pakistan and can be considered a good reference for further analysis.
\end{abstract}

Keywords: Gender role; Gender discrimination; Television advertisement; Commercials content.

\section{Introduction}

Advertising is one of the most influential, attractive and therefore, most widely used media to grab customers' attention. Success of advertisements is largely dependent on demographics of the target audience. Gender, being one of the prominent demographic variables; is the focal point of this study. Gender is multifaceted and frequently incorporated conceptualization in analyzing consumer behavior in undetectable ways (Penaloza, 1994). Symbolic meanings connected with masculinity and femininity within a cultural setting is a crucial factor for advertising strategists who desire to persuade the males or females within a society (Alvesson and Billing, 1997). In order to make important advertising decisions, it is imperative to know about what and how with respect to the ways customers think, process and behave in response to exposure to advertising elements. Gender is a commonly used segmentation strategy as it fulfils numerous criteria for effective segmentation like convenient to identify, ease in accessibility, measurability and profitability (Darley \& Smith, 1995). In a bid to comprehend the linkage between gender and advertising, gender portrayal studies have examined the relationship between gender and advertising in various media such as print (MacKay \& Covell, 1997; Severn, Belch, \& Belch, 1990; Sullivan \& O'Connor, 1988), radio (Alreck, Settle \& Belch, 1982; Debevec \& Iyer, 1986), internet (Knupfer, 1998) and television (Coltrane \& Adams, 1997; McDaniel \& Kinney, 1998; Peirce \& McBride, 1999). Furthermore, a few studies have evaluated the effects of association of gender with products and the brands on the buying trends of males and females (Bellizzi \& Milner, 1991; Elliott, Eccles, \& Hodgson, 1992) and gender in relation to effect of advertising on consumer behavior (Ford, LaTour, and Lundstrom, 1991; Wolburg \& Pokrywczynski, 2001). However majority of the past studies have been 
conducted in developed countries like USA, Japan, Australia, Singapore, Britain, Turkey, and New Zealand. Thus it would be quite interesting to unveil the gender role portrayal in media in a developing country like Pakistan. Advertisement industry as communication solutions provider is expanding its horizon in Pakistan. Multiple media options are available to advertisers such as TV channels, newspapers, magazines, outdoor media, radio, internet and cinema. In addition, several advertising agencies, media houses, production houses, research organizations, creative houses, post-production houses, outdoor advertising agencies, direct marketing companies and printing housing are also serving to fulfill the emerging communication needs. Changing consumption patterns, lifestyles and media habits of consumers push the advertisers and related industry players to produce more creative and specialized advertising campaigns, focusing on well-defined target audience. Increasing need to differentiate a business from the competitors is further adding to the significance of advertising for survival and progress of organizations. With respect to media in Pakistan, television is a very popular medium. Considering this fact, the advertisers spend the most of their advertising budget on television advertisements. According to Gallup and Gilani (2010) the share of advertising spend on Television is 68 percent. Thus, the scope of this study is gender portrayal in television advertisements. Role, importance and contribution of television for advertising can never be denied. It has penetrated deeply in human life and has become a potential area of study because of its expected wider audience than any other medium. Television, having a variety of viewer segments, is considered a very persuasive advertising medium because of its voice, visual and motion combination. Commercials of different brands and product categories nowadays are going on-air on television to gain the attention of target audience. They help customers to remember, recall and retrieve useful information about the brand and stimulate their desire to purchase. In television advertising, gender role portrayal and stereotyping has attracted considerable research interest for the last few decades. A number of studies have addressed these issues in different parts of the world. However, their findings may not be equally useful with respect to their application on target audiences with different demographics and cultural backgrounds.

Pakistan, a country with its unique demographics and cultural values represents one of the most promising consumer markets in the world. It is the world's sixth largest country with a population size of over 180 million that is growing at a rate of $2.03 \%$ a year (Pakistan Economic Survey 2011-2012). Its potential as a growing consumer market makes it a big attraction for not only the businesses around the world, but also for local and international players of advertising industry as well. Moreover, the proportion of females in total Pakistan's population is almost equal to male population (sex ratio of 1.06 male(s)/female in 2011, an estimate quoted by 'CIA - The World Fact book'). Females, who have been traditionally considered less active relative to their male counterparts in outside-the-home activity, are now making their representation in different areas of work and life more visible and contributory. It is expected to enhance their role as an influential consumer market segment for various types of products and services. Keeping in view the aforementioned discussion, this research aims to study the gender role portrayal in television advertisement in Pakistan. The objectives of this research mainly include studying the food advertisement (expected to be gender-neutral advertisement) relative to non-food advertisement, in order to find out gender discrimination (if any). Moreover the association of gender categories with the advertisement content variables, such as, soundtrack level, activity level and aggression level has also been examined. Evidence from a country with a different cultural and social perspective adds to the knowledge diversity in this area of research, having useful implications for key players in advertising industry. As per our knowledge, this is the first attempt in Pakistani consumer market to study the gender role portrayal in television advertisement, so this is going to offer new opportunities for future researchers to further explore this important area of research. This study has been organized as following: In the next section (section 2), a review of some of the published studies highlights the social and business context of research problem on hand and covers the concepts and indicators central to this study. Section 3 clearly describes the research questions for this study, which also represent the complete set of research objectives. Section-4 discusses key areas of research design, including research method (section 4.1), target population and sample selection (section 4.2), key variables (section 4.3), coding procedure (section 4.4), coding reliability (section 4.5) and hypothesis development (section 4.6). Results and findings, discussion, and, conclusion have been reported in sections 5, 6 and 7 respectively. Finally, section 8 discusses opportunities for future research and limitations of this study. 


\section{Literature Review}

Keeping in view the significance of this research area and importance of advertisement and media for organizations in gaining the desired consumer behavior and developing attitudes, research on gender role portrayal in advertisement started since 1970s in USA and in different parts of the world afterwards. A sizeable number of studies found male voiceovers to be dominant in advertisement, such as Furnham and Bitar (1993), Wee et. al., (1995), Mwangi (1996) (except in ads for household products), Siu and Au (1997), Neto and Pinto (1998) and Childs and Maher (2003) with the exception of a few like Uray and Burnaz (2003) who found female voiceovers dominating in Turkish advertisement. Males were portrayed as relatively more dominant characters (Macklin and Kolbe 1983; Hoek and Laurence 1991; Browne 1998); having more control (Browne 1998); mostly delivering end comments (Furnham and Bitar 1993; Neto and Pinto 1998); with higher aggression level (Macklin and Kolbe 1983; Browne 1998); having independent roles/identity (McArthur and Resko 1975; Gilly 1988; Siu and Au 1997; Neto and Pinto 1998); as authorities (Furnham and Bitar 1993; Neto and Pinto 1998; Neto and Santos 2004); more occupationally set (McArthur and Resko 1975; Neto and Pinto 1998; Neto and Santos 2004); employed at managerial positions (Wee et. al. 1995); from middle to high level business executives (Siu and Au 1997); more knowledgeable, possessing more expertise and better rewarded with social and career advancements (McArthur and Resko 1975); more knowledgeable and instrumental (Browne 1998); from middle-age category (Furnham and Bitar 1993; Neto and Pinto 1998); in interviewer roles (Furnham and Bitar 1993); offering factual and opinion arguments and stressing pleasure (Neto and Pinto 1998); outside of residence (Wee et. al. 1995) and as professional entertainers (Siu and Au 1997). Females were portrayed mostly as young in advertisement (Schneider and Schneider 1979; Gilly 1988; Furnham and Bitar 1993; Siu and Au 1997; Neto and Pinto 1998; Uray and Burnaz 2003); in dependent roles (Furnham and Bitar 1993; Siu and Au 1997; Neto and Santos 2004); inside of residence (Schneider and Schneider 1979; Furnham and Bitar 1993; Wee et. al. 1995; Mwangi 1996; Neto and Pinto 1998; Neto and Santos 2004); less employed (Schneider and Schneider 1979; Bretl and Cantor 1988); as low-level workers (Siu and Au 1997); in narrowly defined roles (Schneider and Schneider 1979); in more recreational roles than males (Khair Ullah and Khair Ullah 2009); as product users (Furnham and Bitar 1993; Neto and Pinto 1998); not as authorities but more concerned with appearance (Ford et, al. 1998); and as shy, giggly and unlikely to assert control (Browne 1998). Female ads were also found with quite sound tracks i.e. more quite than neutral ads (Macklin and Kolbe 1983).

McArthur and Resko (1975) found males portrayed as central characters in USA and in contradiction to this Uray and Burnaz (2003) found females portrayed as primary characters in Turkey. However, both genders were equally found portrayed as central characters by Bretl and Cantor (1988) in USA and no significant difference was found between both genders in this regard by Mwangi (1996) in Kenya and Furnham and Li (2008) in Hong Kong. Males were exposed with higher activity level in commercials (Macklin and Kolbe 1983; Browne 1998). They were more active in sports and physical activities while females were relatively inactive (Siu and $\mathrm{Au}$ 1997). Gender role portrayal in advertisement has varied with respect to product category. Males were more portrayed in commercials for auto, hardware, alcohol and financial services (Mwangi 1996) and in commercials for auto and sports (Neto and Pinto 1998) while females were more portrayed in commercials for households, personal or baby products (Mwangi 1996) and in commercials for body and food products (Neto and Pinto 1998). Moreover, male appeared as central character in commercials of products used by either sex while female appeared as central character in commercials of products used by females only (Siu and $\mathrm{Au}$ 1997). Whipple and McManamon (2002) regarded a spokesperson's and announcer's sex as influential in evaluating advertisement for a gender-specific product but not for gender-neutral products, so prominence of men as presenters in the ads for gender-neutral products would be difficult to be justified. Childs and Maher (2003) found greater male-oriented gender preference in food advertisement as compared to non-food advertisement to children although food is considered gender-neutral product category. They viewed it as, more likely, a reflection of cultural bias and outlook of advertisers than a conscious decision. Particularly, they found greater gender preferences with respect to voiceovers, dominant product user and main character roles along with higher activity level in food advertisement as compared to non-food advertisement.

Based on the review of studies above, following key indicators have been selected to be observed in TV advertisements for studying portrayal of both the genders and any gender discrimination therein: 
- Gender of voice-over

- Gender of main product user

- Gender of primary character

- Gender of character, delivering end comments

- Activity level

- Aggression level

- Soundtrack level

Research Questions: Focusing on television commercials, this study aims to answer the following questions: 1 - Is there any gender discrimination in television advertisement being broadcasted in Pakistan?

2- If there is, then,

a- Is it male dominant or female dominant?

b- Is it higher in food advertisement or non-food advertisement?

3- Which gender is more dominant in each of food and non-food advertisement?

4- How gender is associated with soundtrack level, activity level and aggression level in television advertisement?

Representation of gender role may vary across different product categories (Whipple and McManamon 2002; Neto and Pinto 1998). That is why; the selected sample of television commercials was classified into food and non-food advertisement. The reason behind distinguishing food and non-food advertisement was genderneutral nature of food product-category. Hence, it was expected that food commercials would also be genderneutral. Although, literature shows contradictory evidences like male-dominant food advertisement was found by Childs and Maher (2003) in USA while Neto and Pinto (1998) found female dominance in Portuguese food commercials. Keeping in view the expectation and contradictory research evidences, it was interesting to study the gender role portrayal in the advertisement of a gender-neutral product category in a different culture i.e. Pakistan. The next section discusses methodology to answer the above mentioned investigative research questions.

\section{Methodology}

This study is based on content analysis as it has been used in previous researches like Browne (1998) and McArthur \& Resko (1975). Content analysis is a research method where we observe and systematically evaluate the symbolic content of recorded communications like commercials in this study (Kolbe and Burnett 1991). Keeping in view the nature of aim and objectives of this research, and, the relevant extant literature, content analysis was considered the most appropriate method of studying gender role portrayal in television advertisement. It was decided to play selected television commercials for independent coders to get their assessment about the key content variables, in order to collect the required data for fulfilling our research objectives. The selected coders were two business graduates (one male and one female) who were provided appropriate training and practice before starting coding procedure.

Target Population and Sample selection: Target population for this study included all television commercials, which were going on-air through different television channels operating in Pakistan, during the time this research was conducted. From such a large population, a sample of commercials was selected which were broadcasted through some popular television channels operating in Pakistan. The sample of commercials was further classified into Food and Non-Food sub-samples. The five selected entertainment channels were PTV, ATV, GEO Entertainment, TV ONE and HUM TV. For selecting the sample, Each TV channel was watched within the time bracket of 7-11 pm (prime time) daily, for a period of two weeks. Within each hour, ten minutes were allocated to each TV channel. If the allocated time was ended and commercial was still in process, the channel was switched immediately after the commercial was completed. Only those commercials were recorded which were viewed completely. In total, 250 commercials (147 foods and 103 Non-food) were recorded. After excluding duplicates, public service announcements, and those in which main character was not identifiable, the final sample consisted of 103 commercials (54 foods and 49 non-foods) for coding purpose. Food sample consisted of advertisements for general food items and beverages while non-food sample comprised of product categories including: like personal and beauty care, 
telecommunication, household cleaning agents, banking and insurance, household appliances, drugs, and baby care. Almost an equal representation of commercials from both the food and non-food categories in final sample was helpful to make their comparative study justified for further statistical analysis. The particulars of food and non-food samples are as shown in table 1 below:

Table 1: Composition of Advertisement Sample

\begin{tabular}{lll}
\hline Product Category & No. of Commercials & Percentage of Total \\
\hline Food and beverages & 54 & 52 \\
Personal and beauty care & 16 & 15 \\
Telecommunication & 14 & 14 \\
Household cleaning agents & 07 & 07 \\
Banking and insurance & 05 & 05 \\
Household appliances & 04 & 04 \\
Drugs & 02 & 02 \\
Baby Care & 01 & 01 \\
Total & 103 & 100 \\
\hline
\end{tabular}

Key Variables: The recorded television commercials were supposed to be analyzed with respect to key content variables (table 2) which were selected after a careful review of extant literature in this area of research (as discussed earlier in section 2). However, before proceeding further, it was essential to clearly define those content variables so that the coders could accurately identify/rate the presence or absence of attributes, represented by those key variables, in television commercials. The operational definitions of content variables were derived from some pervious researches as given below in Table 2.

Table 2: Description of the Content Variables

\begin{tabular}{|c|c|c|}
\hline Variables & Operational Definition & Source \\
\hline $\begin{array}{l}\text { Product } \\
\text { category }\end{array}$ & The product category being advertised & $\begin{array}{l}\text { Schneider and } \\
\text { Schneider (1979) }\end{array}$ \\
\hline $\begin{array}{l}\text { Main product } \\
\text { user }\end{array}$ & The person handling or consuming the product in the commercial. & Browne (1998) \\
\hline Voiceover & $\begin{array}{l}\text { A voice (or voices) from an unseen source that describes the product } \\
\text { and/or encourages product purchase. }\end{array}$ & Browne (1998) \\
\hline $\begin{array}{l}\text { Primary } \\
\text { character }\end{array}$ & A character with the greatest amount of on-screen time. & $\begin{array}{l}\text { Bretl and Cantor } \\
\text { (1988) }\end{array}$ \\
\hline End comment & $\begin{array}{l}\text { A final brief remark - a single sentence or phrase that delivers a } \\
\text { slogan }\end{array}$ & $\begin{array}{l}\text { Furnham and Bitar } \\
\text { (1993) }\end{array}$ \\
\hline $\begin{array}{l}\text { Soundtrack } \\
\text { level }^{\mathrm{a}}\end{array}$ & $\begin{array}{l}\text { The general mood of the audio soundtrack that includes all audio } \\
\text { elements of the commercial, like, actor's voice, announcer's voice- } \\
\text { over, sound effects, and musical accompaniment. (The usage of } \\
\text { technology and sound volume remain constant throughout). }\end{array}$ & $\begin{array}{l}\text { Macklin and Kolbe } \\
\text { (1983) }\end{array}$ \\
\hline Activity level ${ }^{a}$ & $\begin{array}{l}\text { The extent to which the characters are busy and doing a lot, or, are } \\
\text { passive and quiet. }\end{array}$ & Browne (1998) \\
\hline $\begin{array}{l}\text { Level of } \\
\text { aggressiona }^{\text {a }}\end{array}$ & $\begin{array}{l}\text { Acting against another person or thing: hitting, throwing, grabbing, } \\
\text { loud or abusive talk, face making, and determined behavior (as in } \\
\text { aggressively pursuing a goal). }\end{array}$ & Browne (1998) \\
\hline
\end{tabular}

aActivity level, sound track level and aggression level were rated on a scale of 1 (lowest) to 7 (highest). Other variables are categorical.

Coding Procedure: The coding procedure was modeled on that of Bretl and Cantor (1988), Furnham and Bitar (1993), and McArthur and Resko (1975). One business graduate was asked to be the main coder of commercials. Another business graduate also coded all the sampled commercials to verify the reliability of first coder. However, none of the coders was informed about who the main coder was, in order to avoid any possible biasness in their assessments. As the advertisements were taped, multiple replays were used to analyze those advertisements because of less reliance on coder's abilities to process information quickly. 
Clear instructions were given to both coders about the definition of variables and use of the coding sheet prior to viewing the commercials. Coders were not permitted to discuss the advertisements between themselves to ensure originality of observation. Moreover, a practice session was arranged for coders to make sure that they were fully aware of what they were supposed to do. Each coder practiced coding ten commercials in the practice session and two authors were available to answer any of the queries about the variables and coding procedure. The pre-coding task orientation and practice by coders helped to control for any alternate explanations of content variables used in this study. Moreover, the description of content variables (Table II) remained with each coder throughout the coding process for ruling out there any alternate understanding of key variables.

Coding Reliability: The agreement between the coders was assessed by the method proposed by Perreault and Leigh (1989). As stated above, along with the main coder, a second coder was also asked to code the commercials just to ensure the reliability of first coder. Coding results of second coder were, therefore, helpful to judge the quality of primary coder's decisions. Reliability index, calculated in this regard, for each of the four categorical study variables is reported in table 3 below. It ranges from 0.90 (for 'gender of voice over') to 0.97 (for 'end comments'), which, clearly indicates high level of inter-coder reliability in their independent assessments of key content variables.

Table 3: Inter-rater Reliability

\begin{tabular}{lllll}
\hline Variables & $\mathbf{N}$ & $\mathbf{F}_{\mathbf{0}}$ & $\mathbf{K}$ & $\mathbf{I}_{\mathbf{R}}$ \\
\hline Main Product user & 103 & 95 & 4 & .95 \\
Gender of Voiceover & 103 & 89 & 4 & .90 \\
Primary character & 103 & 96 & 4 & .95 \\
End comments & 103 & 99 & 4 & .97 \\
\hline
\end{tabular}

Notes: $I_{R}=\left\{\left[\left(F_{0} / N\right)-(1 / k)\right][k /(k-1)]\right\}^{0.5}$, for $\left(F_{0} / N\right) \geq(1 / k)$, where $I_{R}=$ reliability index, $\mathrm{k}=$ number of categories, $\mathrm{F}_{0}=$ number of agreements, $\mathrm{N}=$ number of observations

Hypothesis development: To answer the research questions (as stated in section 3) through further statistical analysis, hypotheses were developed involving each of the selected content variables. For first four categorical content variables i.e. main product user, voiceover, primary character and end comments, the main hypothesis was: "the food advertisement has less gender differences than in non-food advertisement". The respective hypotheses for these variables are specified below:

H1: Food commercials have less gender differences in main product user as compared to non-food commercials.

H2: Food commercials have less gender differences in voiceover as compared to non-food commercials.

H3: Food commercials have less gender differences in primary character as compared to non-food commercials.

H4: Food commercials have less gender differences in delivery of end comments as compared to non-food commercials.

Three other content variables i.e. sound track level, activity level and aggression level were coded using seven-point continuous numeric scale (rather than categorical scale), as used by like Macklin and Kolbe (1983) rather than categorical scale. According to some previous studies (Browne 1998) male dominant advertisements are expected to exhibit higher levels of sound track, activity and aggression, therefore we hypothesize the following:

H5: Male-dominant commercials exhibit higher mean soundtrack level as compared to female-dominant commercials.

H6: Male-dominant commercials exhibit higher mean activity level as compared to female-dominant commercials.

H7: Male-dominant commercials exhibit higher mean aggression level as compared to female-dominant commercials.

For this purpose, arithmetic means of all the gender options (i.e. male, female, both, and none) were calculated for each of the four categorical content variables (i.e. main product user, voiceover, primary character and end comment) against each of soundtrack level, activity level and aggression level (Table 8). 


\section{Results}

Main Product User: Main product user is the person handling or consuming the advertised product in the commercial (Browne, 1998). In this study, for each of the categorical content variables, the coders (while watching each commercial) were required to classify their responses into any of the following four categories: male, female, both or none. Results (as shown below in table 4) reveal an overall female dominance in Pakistani television advertisement with respect to main product user favoring the existence of gender discrimination in advertisement. This female dominance is found in both food and non-food commercials. Findings suggest gender discrimination in food advertisement is less as compared to non-food advertisement, so $\mathrm{H} 1$ is supported. In $33 \%$ of food advertisement sample, females are found to be the main product users while $28 \%$ food ads portrayed males as main product users. For non-food product category, $49 \%$ commercials portrayed females, while $29 \%$ commercials portrayed males as main product users. The results, apparently, favor the existence of higher female-oriented gender biasness exists in non-food television advertisement as compared to food television advertisement. However, the relationship between category of product advertised and gender role is not found to be statistically significant $(p=0.218)$. It reveals that gender role is food advertisement is not different from that in non-food advertisement with respect to main product user. So H1 is not supported statistically. Our findings contradict Childs and Maher (2003) who found males as dominant product users in food advertisement, and that male dominance was higher than that in non-food advertisement. Their research focused only on television advertisement targeting children, but in this study, selected sample of television commercials was targeting a diversified range of target audience, and not only the children. Moreover, difference in point of time and research context may provide some alternate explanations for the difference in findings of both the studies.

Table 4: Gender of Main Product User

\begin{tabular}{lllllll}
\hline & Food & \% & Non-Food & \% & Total & \% \\
\hline Female & 18 & 33 & 25 & 49 & 43 & 42 \\
Male & 15 & 28 & 13 & 29 & 28 & 27 \\
Both & 17 & 32 & 08 & 14 & 25 & 24 \\
None & 04 & 07 & 03 & 06 & 07 & 7 \\
Total & 54 & 100 & 49 & 100 & 103 & 100 \\
\hline
\end{tabular}

Note: $\chi^{2}=4.43 ; p=0.218$

Table 5: Gender of Voiceover

\begin{tabular}{llllllc}
\hline & Food & \% & Non-Food & \% & Total & \% \\
\hline Female & 06 & 11 & 09 & 18 & 15 & 14 \\
Male & 39 & 72 & 35 & 72 & 74 & 72 \\
Both & 06 & 11 & 04 & 08 & 10 & 10 \\
None & 03 & 06 & 01 & 02 & 04 & 04 \\
Total & 54 & 100 & 49 & 100 & 103 & 100 \\
\hline
\end{tabular}

Note: $\chi^{2}=1.978 ; p=0.577$

Gender of Voiceover: The voiceover is defined as a voice (or voices) from an unseen source that describes the product and/or encourages product purchase (Browne, 1998). Results (as shown in table 5) revealed an overall higher male voiceover that existed for both food and non-food TV advertisements. A considerably higher $(72 \%)$ male voiceover is found in each of the advertised product categories as compared to just $11 \%$ and $18 \%$ female voiceover in food and non-food advertisement respectively. However, a better female representation is found in non-food as compared to food advertisement. Apparently, these results suggest that gender discrimination in food advertisement with respect to voiceover is not less than that of non-food advertisement; rather it is found to be slightly higher. However, there exists no significant relationship between product category (i.e. food or non-food) and gender role with respect to voiceover $(\mathrm{p}=0.577)$. Therefore, $\mathrm{H} 2$ is not statistically supported and no significant difference in gender of voice over has been found in both the categories of advertised products (i.e. food and non-food). Overall results report the 
existence of gender discrimination with respect to voice over, where males dominate more in both the food and non-food commercials. This trend of voice over suggests that males are expected to be more persuasive and able to communicate easily, that is why, male voice over is found to be dominant in Pakistani advertisement. Our findings are consistent with a number of evidences available in extant literature including: Furnham and Bitar (1993), Wee et. al., (1995), Siu and Au (1997), Neto and Pinto (1998), and, Childs and Maher (2003), with a few exceptions such as Uray and Burnaz (2003), who, found female voiceovers dominating in Turkish advertisement.

Gender of Primary Character: Bretl and Cantor (1988) defined primary character as a character with the greatest amount of on-screen time. In this study, results favor an overall existence of gender discrimination with respect to primary character in television commercials, where males are found more dominant (as shown in table 6). However, this male dominance is associated only with food commercials (52\% commercials portrayed males as primary characters, against $22 \%$ commercials, which portrayed females as primary characters). In case of non-food commercials revealed a higher dominance of female as a primary character is reported $(53 \%$ commercials portrayed females as primary characters, against $31 \%$ commercials, which portrayed males as primary characters). Results also portray higher gender discrimination in food advertisement as compared to non-food advertisement (in contradiction to H3), with a significant relationship ( $\mathrm{p}=0.022$ ) between type of product commercial (i.e. food or non-food) and gender role (with respect to primary character). Thus, it can be suggested that the gender role portrayal of primary character significantly varies for both the categories of advertised products (food and non-food). Looking at the results, as stated above, $\mathrm{H} 3$ is being rejected. Our findings are, somehow, consistent with Childs and Maher (2003) who found greater gender preference for males in food advertisement with respect to main character portrayed in television commercials. The overall dominance of male as a primary character is also consistent with McArthur and Resko (1975), who analyzed television commercials in USA. However, a later study in USA by Bretl and Cantor (1988) found both the genders equally portrayed as central characters. In Pakistan, the social values may explain the male dominance in food advertisement that is expected to be a gender-neutral category.

Table 6: Gender of Primary Character

\begin{tabular}{|c|c|c|c|c|c|c|}
\hline & Food & $\%$ & Non-Food & $\%$ & Total & $\%$ \\
\hline Female & 12 & 22 & 26 & 53 & 38 & 37 \\
\hline Male & 28 & 52 & 15 & 31 & 43 & 42 \\
\hline Both & 12 & 22 & 07 & 14 & 19 & 18 \\
\hline None* & 02 & 04 & 01 & 02 & 03 & 03 \\
\hline Total & 54 & 100 & 49 & 100 & 103 & 100 \\
\hline
\end{tabular}

Note: $\chi 2=9.593 ; p=0.022$

* 'None' refers to the situation where it is difficult to identify primary character and no one had on-camera appearance for more than three seconds.

Table 7: Gender associated with 'End Comment'

\begin{tabular}{lllllll}
\hline & Food & \% & Non-Food & $\mathbf{\%}$ & Total & \% \\
\hline Female & 09 & 17 & 10 & 21 & 19 & 18 \\
Male & 24 & 44 & 29 & 59 & 53 & 52 \\
Both & 01 & 02 & 05 & 10 & 06 & 06 \\
None & 20 & 37 & 05 & 10 & 25 & 24 \\
Total & 54 & 100 & 49 & 100 & 103 & 100 \\
\hline
\end{tabular}

Note: $\chi^{2}=11.977 ; p=0.007$

End Comment: "A final brief remark - a single sentence or phrase that delivered a slogan" is defined as the end comment (Furnham and Bitar, 1993). For studying the gender role portrayal in television advertisement, the coders were asked to identify which gender delivered end comment in selected commercials. Delivery of end comment was classified into four gender-based categories: by male, female, both or none. Results (Table 7) provided evidence that males dominate in delivering end comment, in both; the food and non-food 
advertisement. Our finding is consistent with that of Furnham and Bitar (1993) who studied British television advertisement, and, Neto and Pinto (1998) who studied television advertisement in Portugal. In this study, the relationship between product category being advertised (i.e. food or non-food) and role of gender has been found statistically significant $(p=0.007)$ i.e. gender role portrayal based on delivery of end comment significantly varies for food and non-food advertisement categories. Moreover, gender discrimination is found less in food advertisement as compared to non-food advertisement; hence, $\mathrm{H} 4$ is being supported. Keeping in view the above results, it can be suggested that there exists gender discrimination in television advertisement with respect to delivery of end comments and this discrimination is favoring males in both the food and nonfood advertisement categories.

Soundtrack, Activity level and Aggression level: The results reported in table 8 favor the association of male gender with the higher activity level and aggression level as compared to that of female characters. Male-oriented commercials have already been found to portray higher activity and aggression levels in the extant literature (Verna 1975, Welch et al. 1979). Our results also support the findings of Browne (1998) and Macklin and Kolbe (1983). For soundtrack level, although, literature supports female commercials to be significantly more quite than the male commercials (Verna 1975), we find mixed results for this content variable. The above stated results favor $\mathrm{H} 6$ and H7. However, $\mathrm{H} 5$ is not being supported. Comparing overall ratings of these three content variables, soundtrack level has been rated the highest, followed by activity and aggression levels respectively, for the selected sample of television commercials. Improvement and innovation in sound technology can be an explanation behind such high rating for the soundtrack levels in advertisement.

Table 8: Soundtrack, activity and aggression levels

\begin{tabular}{|c|c|c|c|c|c|c|}
\hline \multirow{2}{*}{$\begin{array}{l}\text { Categorical } \\
\text { Content } \\
\text { Variables }\end{array}$} & \multicolumn{2}{|c|}{ Soundtrack Level ${ }^{*}$} & \multicolumn{2}{|c|}{ Activity Level $^{*}$} & \multicolumn{2}{|c|}{ Aggression Level* } \\
\hline & Mean & $\begin{array}{l}\text { Standard } \\
\text { Deviation }\end{array}$ & Mean & $\begin{array}{l}\text { Standard } \\
\text { Deviation }\end{array}$ & Mean & $\begin{array}{l}\text { Standard } \\
\text { Deviation }\end{array}$ \\
\hline \multicolumn{7}{|c|}{ Main Product User } \\
\hline Female & 5.19 & 1.314 & 4.37 & 1.496 & 3.84 & 1.588 \\
\hline Male & 4.93 & 1.464 & 5.11 & 1.618 & 4.25 & 1.624 \\
\hline Both & 5.48 & 1.229 & 4.60 & 1.500 & 3.68 & 1.676 \\
\hline None & 4.57 & 1.718 & 3.29 & 2.360 & 2.43 & 1.813 \\
\hline Total & 5.15 & 1.368 & 4.55 & 1.637 & 3.82 & 1.667 \\
\hline \multicolumn{7}{|l|}{ Voiceover } \\
\hline Female & 5.27 & 0.884 & 4.40 & 1.454 & 3.67 & 1.345 \\
\hline Male & 5.04 & 1.466 & 4.55 & 1.648 & 3.76 & 1.719 \\
\hline Both & 5.70 & 1.059 & 5.30 & 1.418 & 4.90 & 1.370 \\
\hline None & 5.25 & 1.700 & 3.25 & 2.217 & 2.75 & 1.708 \\
\hline Total & 5.15 & 1.368 & 4.55 & 1.637 & 3.82 & 1.667 \\
\hline \multicolumn{7}{|c|}{ Main Character } \\
\hline Female & 5.08 & 1.605 & 4.16 & 1.590 & 3.46 & 1.626 \\
\hline Male & 5.19 & 1.220 & 4.77 & 1.631 & 4.30 & 1.626 \\
\hline Both & 5.37 & 1.012 & 5.16 & 1.259 & 3.74 & 1.593 \\
\hline None & 4.25 & 2.062 & 3.00 & 2.449 & 2.25 & 1.500 \\
\hline Total & 5.15 & 1.368 & 4.55 & 1.637 & 3.82 & 1.667 \\
\hline \multicolumn{7}{|c|}{ End Comments } \\
\hline Female & 5.16 & 1.068 & 4.32 & 1.293 & 3.79 & 1.398 \\
\hline Male & 5.25 & 1.371 & 4.68 & 1.591 & 3.85 & 1.645 \\
\hline Both & 5.00 & 1.414 & 5.33 & 1.366 & 4.33 & 2.338 \\
\hline None & 4.96 & 1.594 & 4.28 & 1.990 & 3.64 & 1.800 \\
\hline Total & 5.15 & 1.368 & 4.55 & 1.637 & 3.82 & 1.667 \\
\hline
\end{tabular}

*Note: seven-point scales: 1 = low, 7 = high

Discussion: Gender discrimination is an emerging area of study in management and social sciences, especially in advertising. So far, a considerable research work on gender discrimination in advertisement has been conducted but mostly in developed countries. This study is first of its kind in Pakistan on gender 
discrimination that has been concluded using a well defined methodology and appropriate analytical tools. In this study, major research question is, whether there is any gender discrimination present in television advertisement or not. In addition, if there is, then whether it is male dominated or female dominated. Moreover, gender role in food and non-food advertisement has also been studied and compared. The results reported existence of gender discrimination in Pakistani television advertisement, where males dominated more. This male dominance somehow existed in both food and non-food advertisements, however it was found higher in food commercials. Significant relationship between advertised product category and gender role was found with respect to two categorical content variables: primary character and end comments. However, food items are considered gender-neutral, as both men and women can equally use them, but still we found higher gender discrimination (in form of male dominance) in food advertisement as compared with non-food advertisement, with respect to gender of primary character. However, higher gender discrimination (male-dominant) in non-food advertisement was found as compared with food advertisement, with respect to delivery of end comment. The reason for male dominance in Pakistani television advertisement is expected to lie in cultural and social values. There are a number of viewers in our society who do not favor the presence or exposure of females in television commercials. Heads of the families are mostly males that are supposed to take the major decisions or play the role of key influencers. These social norms and attitudes are very much visible in advertisement being broadcasted through television channels operating in Pakistan. This factor is expected to contribute significantly towards male-dominance-based gender discrimination in advertisement. Some earlier studies (Browne 1998) found male dominant advertisements, exhibiting higher levels of sound track, activity and aggression levels. Our results are consistent with the findings of these studies except for soundtrack level. Male dominant TV advertisements exhibit higher activity and aggression levels as compared to female dominant TV advertisements. We found mixed results regarding sound track level for both gender categories i.e. male and female. However, sound track level was recorded higher on scale for both gender groups. Rapidly improving sound track technology can be studied as a potential variable behind such phenomenon.

\section{Conclusion}

The culture where females have continued to gain equality and balanced representation, gradually, in all areas of work, it seems interesting to find male dominance, particularly in gender neutral categories such as food advertisement. In this regard this study is also consistent with the findings of Peirce and McBride (1999) and Bartsch, Burnett, Diller, and Rankin-Williams (2000) who reported that males represent television advertisements more than the females; moreover, males are preferred as spokes characters and are remembered for long as compared to their female counterparts. This study has useful implications for copywriters, art workers, ad producers, advertising agencies and advertisers. It would help these key players in advertising industry to get an idea about gender discrimination in TV commercials, providing a comparative analysis of gender role portrayal in food and non-food advertisement. It would also help advertising managers for self-regulation of their advertising campaigns with respect to gender role. Advertising people must, however, know the forces of traditional culture values and preferences of target audience while planning the ads and forecasting their impact. Such valuable knowledge of culture and audience preferences can provide a better base for self-regulation of advertising campaigns.

Future Research and Limitations: This study reflects the true picture of gender discrimination in Pakistani television advertisement. Here, findings provide directions for future studies in this area (particularly in Pakistan), for example: trend analysis of gender role portrayal in Pakistani advertisement and its comparison with that in other countries, impact of socio-cultural variables on gender role in advertisement, and gender role portrayal in other types of media i.e. print, outdoor and internet. Due to resources constraints, this study was not able to get a larger sample of television commercials, which could have further strengthened our findings. Because of this limitation, we had to make some compromises in statistical analysis, such as, using chi-square statistic with low frequencies in some cells. Future researchers may improve sample selection by increasing the sample size. They may also increase the representativeness of the sample through selection of television channels or other media vehicles using some well-defined objective/scientific criteria. Providing original data for television advertisement in Pakistan, this study may be considered a useful reference for further analysis in future research. 


\section{References}

Alreck, P. L., Settle, R. B. \& Belch, M. A. (1982). Who Responds to Gendered Ads, and How? Journal of Advertising Research, 22(2), 25-32.

Alvesson, M. \& Billing, Y. (1997). Understanding Gender and Organizations. London: Sage.

Bartsch, R. A., Burnett, T., Diller, T. R. \& Rankin-Williams, E. (2000). Gender Representation in Television Commercials: Updating and Update. Sex Roles, 43(9/10), 735-743.

Bellizzi, J. A. \& Milner, L. (1991). Gender Positioning of a Traditionally Male-Dominant Product. Journal of Advertising Research, 31(3), 72-79.

Bretl, D. J. \& Cantor, J. (1988). The portrayal of men and women in U.S. television commercials: A recent content analysis and trends over 15 years. Sex Roles, 18, 595-609.

Browne, B. A. (1998). Gender stereotypes in advertising on children's television in the 1990s: A cross-national analysis. Journal of Advertising, 27, 83-96.

Childs, N. M. \& Maher, J. K. (2003). Gender in food advertising to children: Boys eat first. British food journal, 105(7), 408-419.

CIA Fact Book. (2012). Pakistan. Retrieved June 21, 2012 from the CIA World Fact Book website: https://www.cia.gov/library/publications/the-world-factbook/geos/pk.html

Coltrane, S. \& Adams, M. (1997). Work-Family Imagery and Gender Stereotypes: Television and the Reproduction of Difference. Journal of Vocational Behavior, 50(2), 323-347.

Darley, W. K. \& Smith, R. E. (1995). Gender Differences in Information Processing Strategies: An Empirical Test of the Selectivity Model in Advertising Response. Journal of Advertising, 24(1), 41-56.

Debevec, K. \& Iyer, E. (1986). The Influence of Spokespersons in Altering a Product's Gender Image: Implications for Advertising Effectiveness. Journal of Advertising, 15(4), 12-20.

Elliott, R., Eccles, S. \& Hodgson, M. (1992). Gender Repositioning in Advertising: A Semiotic Analysis. Paper presented in Proceedings of the Annual Conference of the European Marketing Academy, K. G. Grunert and D. Fuglede, eds. Denmark: European Marketing Academy.

Ford, J. B., LaTour, M. S. \& Lundstrom, W. J. (1991). Contemporary Women's Evaluation of Female Role Portrayals in Advertising. Journal of Consumer Marketing, 8(1), 15-28.

Ford, J. B., Voli, P. K., Honeycutt, E. D. \& Casey, S. L. (1998). Gender role portrayal in Japanese advertising: a magazine content analysis. Journal of Advertising, 27(1), 113-24.

Furnham, A. \& Bitar, N. (1993). The stereotype portrayal of men and women in British advertisements. Sex Roles, 29(3/4), 297-310.

Furnham, A. \& Li, J. (2008). Gender portrayal in food and beverage advertisements in Hong Kong: a content analytic study. Young Consumers, 9(4), 297-307.

Gallup, S. \& Gilani, P. (2010). Advertising Expenditure (Adex) in Pakistan. Special Annual Edition 2010. Islamabad : Author

Gilly, M. C. (1988). Sex Roles in Advertising: A comparison of television advertisements in Australia, Mexico, and the United States. Journal of Marketing, 52(2), 75-85.

Hoek, J. \& Laurence, K. (1991). Television Advertising to Children: An Analysis of Selected New Zealand Commercials. Marketing Bulletin, 4, 19-29.

Khairullah, D. H. Z. \& Khairullah, Z. Y. (2009). Cross-cultural analysis of gender roles: Indian and US advertisements. Asia Pacific Journal of Marketing and Logistics, 21(1), 58-75.

Knupfer, N. (1998). Gender Divisions across Technology Advertisements and the WWW: Implications for Educational Equity. Theory into Practice, 37(1), 54-63.

Kolbe, R. H. \& Burnett, M. S. (1991). Content-analysis research: an examination of applications with directives for improving research reliability and objectivity. Journal of Consumer Research, 18(2), 243-250.

MacKay, N. J. \& Covell, K. (1997). The Impact of Women in Advertisements on Attitudes toward Women. Sex Roles, 36(9/10), 573-583.

Macklin, C. \& Kolbe, R. H. (1983). Sex role stereotyping in children's advertising: current and past trends. Journal of Advertising, 13(2), 34-42.

McArthur, L. Z. \& Resko, B. G. (1975). The portrayal of men and women in American television commercials. The Journal of Social Psychology, 97, 209-220.

McDaniel, S. R. \& Kinney, L. (1998). The Implications of Recency and Gender Effects in Consumer Response to Ambush Marketing. Psychology and Marketing, 15(4), 385-403.

Ministry of Finance. (2012). Pakistan Economic Survey 2011-2012. Islamabad, Pakistan: Author. 
Mwangi, M. W. (1996). Gender Roles Portrayed in Kenyan Television Commercials. Sex Roles, 34, 205-214.

Neto, F. \& Pinto, I. (1998). Gender stereotypes in Portuguese television advertisements. Sex Roles, 39, 153-65.

Neto, F. \& Santos, A. (2004). Gender role stereotyping in radio advertisements: A Portuguese and crossnational analysis. Journal of Radio Studies, 11, 131-145.

Peirce, K. \& McBride, M. (1999). Aunt Jemima Isn't Keeping Up with the Energizer Bunny: Stereotyping of Animated Spokes-Characters in Advertising. Sex Roles, 40(11/12), 959-966.

Penaloza, L. (1994). Crossing Boundaries/Drawing Lines: A Look at the Nature of Gender Boundaries and their Impact on Marketing Research. International Journal of Research in Marketing, 11(4), 359-379.

Perreault, W. D. \& Leigh, L. E. (1989). Reliability of nominal data based on qualitative judgments. Journal of Marketing Research, 26(2), 135-148.

Schneider, K. C. \& Schneider, S. B. (1979). Trends in sex roles in television commercials. Journal of Marketing, 43, 79-84.

Severn, J., Belch, G. E. \& Belch, M. A. (1990). The Effects of Sexual and Non-Sexual Advertising Appeals and Information Level on Cognitive Processing and Communication Effectiveness. Journal of Advertising, 19(1), 14-22.

Siu, W. \& Au, A. K. (1997). Women in advertising: a comparison of television advertisements in China and Singapore. Marketing Intelligence and Planning, 15, 235-243.

Sullivan, G. L. \& O'Connor, P. J. (1988). Women's Role Portrayals in Magazine Advertising: 1958-1983. Sex Roles, 18(3/4), 181-188.

Uray, N. \& Burnaz, S. (2003). An Analysis of the Portrayal of Gender Roles in Turkish Television Advertisements. Sex Roles, 48(1/2), 77-87.

Verna, M. E. (1975). The Female Image in Children's TV Commercials. Journal of Broadcasting, 19(3), 301-309.

Wee, C., Choong, M. \& Tambyah, S. (1995). Sex role portrayal in television advertising: A comparative study of Singapore and Malaysia. International Marketing Review, 12, 49-64.

Welch, R. L., Aletha, H. S., John, C. W. \& Robert, P. (1979). Subtle Sex-Role Cues in Children's Commercials. Journal of Communication, 29(3), 202-209.

Whipple, T. W. \& McManamon, M. K. (2002). Implications of using male and female voices in commercials: An explanatory study. Journal of Advertising, 31, 79 - 91.

Wolburg, J. M. \& Pokrywczynski, J. (2001). A Psychographic Analysis of Generation Y College Students. Journal of Advertising Research, 41(5), 33-52. 